Article

\title{
Cytoprotection against Oxidative Stress by Methylnissolin-3- $O-\beta$-D-glucopyranoside from Astragalus membranaceus Mainly via the Activation of the Nrf2/HO-1 Pathway
}

\author{
Xiaohua Wu ${ }^{1}$, Jian $\mathrm{Xu}^{2}$, Yousheng Cai ${ }^{1,3}$, Yuejun Yang ${ }^{2}$, Yuancai Liu ${ }^{2, *}$ and Shugeng Cao ${ }^{1, *(D)}$ \\ 1 Department of Pharmaceutical Sciences, Daniel K. Inouye College of Pharmacy, University of Hawai'i at Hilo, \\ Hilo, HI 96720, USA; xiaohua3@hawaii.edu (X.W.); caiyoush@hawaii.edu (Y.C.) \\ 2 Hubei Provincial Key Laboratory of Quality and Safety of Traditional Chinese Medicine Health Food, \\ Jing Brand Research Institute, Jing Brand Co., Ltd., Daye 435100, China; xujian@jingpai.com (J.X.); \\ yyj@jingpai.com (Y.Y.) \\ 3 Institute of TCM and Natural Products, School of Pharmaceutical Sciences, Wuhan University, 185 Donghu \\ Road, Wuhan 430071, China \\ * Correspondence: lyc@jingpai.com (Y.L.); scao@hawaii.edu (S.C.); Tel.: +86-71-4876-8056 (Y.L.); \\ $+1-808-981-8010$ (S.C.)
}

Citation: Wu, X.; Xu, J.; Cai, Y.; Yang, Y.; Liu, Y.; Cao, S. Cytoprotection against Oxidative Stress by Methylnissolin-3-O- $\beta$-Dglucopyranoside from Astragalus membranaceus Mainly via the Activation of the Nrf2/HO-1 Pathway. Molecules 2021, 26, 3852. https://doi.org/10.3390/ molecules 26133852

Academic Editors: Gilles Comte and Domenico Trombetta

Received: 16 May 2021

Accepted: 16 June 2021

Published: 24 June 2021

Publisher's Note: MDPI stays neutra with regard to jurisdictional claims in published maps and institutional affiliations.

Copyright: (c) 2021 by the authors. Licensee MDPI, Basel, Switzerland. This article is an open access article distributed under the terms and conditions of the Creative Commons Attribution (CC BY) license (https:/ / creativecommons.org/licenses/by/ $4.0 /)$.

\begin{abstract}
Astragalus membranaceus is a famous herb found among medicinal and food plants in East and Southeastern Asia. The Nrf2-ARE assay-guided separation of an extract from Jing liqueur led to the identification of a nontoxic Nrf2 activator, methylnissolin-3-O- $\beta$-D-glucopyranoside (MNG, a component of $A$. membranaceus). Nrf2 activation by MNG has not been reported before. Using Western Blot, RT-qPCR and imaging, we investigated the cytoprotective effect of MNG against hydrogen peroxide-induced oxidative stress. MNG induced the expression of Nrf2, HO-1 and NQO1, accelerated the translocation of Nrf2 into nuclei, and enhanced the phosphorylation of AKT. The MNG-induced expression of Nrf2, HO-1, and NQO1 were abolished by Nrf2 siRNA, while the MNG-induced expression of Nrf2 and HO-1 was abated and the AKT phosphorylation was blocked by LY294002 (a PI3K inhibitor). MNG reduced intracellular ROS generation. However, the protection of MNG against the $\mathrm{H}_{2} \mathrm{O}_{2}$ insult was reversed by Nrf2 siRNA with decreased cell viability. The enhancement of Nrf2 and HO-1 by MNG upon $\mathrm{H}_{2} \mathrm{O}_{2}$ injury was reduced by LY294002. These data showed that MNG protected EA.hy926 cells against oxidative damage through the Nrf2/HO-1 and at least partially the PI3K/Akt pathways.
\end{abstract}

Keywords: Astragalus membranaceus; MNG; Nrf2; PI3K; EA.hy926 cells

\section{Introduction}

Oxygen is essential for life, but the generation of excess ROS can cause many health problems, such as cancer, rheumatoid arthritis, cardiovascular disease, kidney diseases, respiratory disease, sexual maturation, and neurological disease (e.g., Alzheimer's disease, Parkinson's disease, aging and many other neural disorders) [1,2]. The serious threat of oxygen toxicity is often overlooked because all aerobic organisms, including mammals, have intrinsic mechanisms that protect against oxidative damage. To inhibit the oxidative stress that can cause many health problems, one justifiable strategy is to promote the expression of Nrf2 (nuclear factor erythroid 2-related factor 2) and its downstream antioxidant enzymes (e.g., HO-1) [3,4]. The Nrf2 transcription factor, through binding to antioxidant response elements (AREs), induces the expression of a group of downstream anti-oxidant and detoxifying enzymes that protect against oxidative damage and also provide protection against toxic foreign chemical substances through phase II enzyme modification [5-7]. Keap1 (Kelch ECH associating protein 1) is a repressor protein that binds to Nrf2 and 
promotes its degradation by the ubiquitin proteasome pathway [8]. When cells undergoes stress, Keap1 is unable to target Nrf2 due to the change of certain cysteine residues, leading to the phosphorylation and stabilization of Nrf2 in the cytoplasm followed by translocation and accumulation of Nrf2 in the nucleus [9]. In the nucleus, Nrf2 forms a heterodimeric complex with the small Maf (musculoaponeurotic fibrosarcoma) proteins to promote the expression of ARE-mediated antioxidant and detoxifying genes, including heme oxygenase 1 (HO-1), NAD(P)H:quinone oxidoreductase 1 (NQO1), thioredoxin reductase 1 (TrxR1), glutamate-cysteine ligase (GCL), thioredoxin 1 (Trx1) and so on [10]. The phosphoinositide 3-kinase (PI3K) / Akt pathway is another important signaling pathway and its activation could recover the redox balance, defend the oxidative stress, and promote cell survival [11]. It has been reported that the PI3K/Akt pathway could regulate Nrf2 translocation and HO-1 synthesis, and play key roles in regulating Nrf2-ARE-dependent protection [12].

Jing liqueur is a beverage containing biologically active compounds from some herbs, including Astragalus membranaceus, etc. [13]. In a previous study, we have isolated $189 \mathrm{mi}-$ nor compounds, among which 18 compounds activated Nrf2 at $40 \mu \mathrm{g} / \mathrm{mL}$ in an Nrf2-ARE assay [13]. In our continuing search for Nrf2 activators from the Jing liqueur, we obtained an extract. Nrf2 assay-guided separation led to the isolation of methylnissolin-3-O- $\beta$-Dglucopyranoside [14] (MNG, Figure 1), a new Nrf2 activator that significantly activated Nrf2 at $40 \mu \mathrm{g} / \mathrm{mL}$. MNG was much more active than any of the previously isolated $18 \mathrm{Nrf2}$ activators [13]. MNG was a component of A. membranaceus, which is a well-known tonic herb that has been used as both a traditional Chinese medicine and a food or beverage. Traditionally, A. membranaceus is primarily used as a lung tonic while its contemporary use mainly focuses on its immunomodulating, antioxidant, and anti-inflammatory, as well as anticancer effects [15]. In 2005, An and his coworkers investigated the neuroprotective roles and direct antioxidant effects of isoflavonoids isolated from the roots of $A$. mongholicus Bunge (Leguminosae) by using the PC12 cell model (a cell line derived from a pheochromocytoma of the rat adrenal medulla) and DPPH (1,1-diphenyl-2-picrylhydrazyl) assay [16], but MNG showed no obvious neuroprotective capability in the PC12 cell-based assay and no apparent scavenging activity against DPPH radicals [16]. In 2014, a research group in Taiwan studied the synergistic antioxidant activity of A. membranaceus and Paeonia lactiflora and the research group identified 17 antioxidant components, but the activities of the identified compounds including MNG were not investigated [17]. We argue that MNG can enhance the expression of Nrf2, increase the Nrf2 nuclear translocation, activate Nrf2 target proteins, and regulate cytoprotective responses to the stress caused by reactive oxygen species (ROS). We also anticipate that MNG may have some effect on the PI3K/Akt pathway involved in controlling the Nrf2-ARE activity.

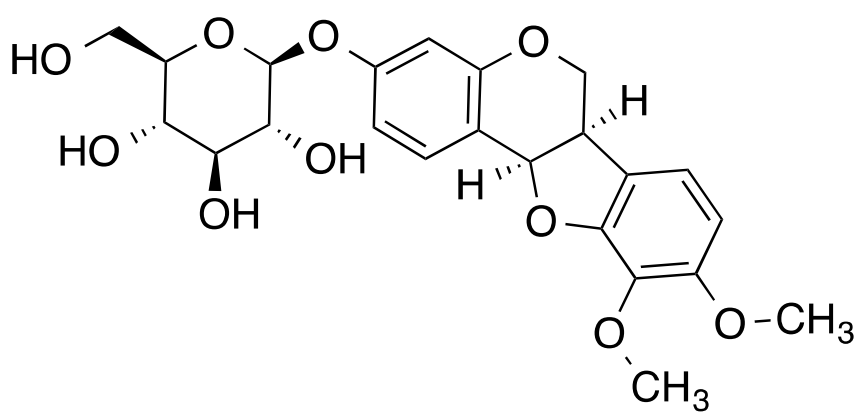

Figure 1. Structure of methylnissolin-3-O- $\beta$-D-glucopyranoside (MNG, CAS Registry Number 9436742-7).

In this study, we investigated the effects of MNG on the Nrf2 pathway with human EA.hy926 cells (a type of HUVEC, human umbilical vein endothelial cells), evaluated the protective effect of MNG on the oxidative stress-induced injury of the EA.hy926 cells, 
and examined whether MNG had an antioxidative capacity through the activation of the PI3K/Akt pathway.

\section{Results}

\subsection{Identification of MNG as an Nrf2 Activator and Its Cytotoxicity on EA.hy926 Cells}

In our previous study, we isolated 189 minor compounds from Jing liqueur [13]. Most of the compounds were assayed on Nrf2-HepG2 stable cells using the luciferase system to identify Nrf2 activators at $40 \mu \mathrm{g} / \mathrm{mL}$ in triplicate [13]. Eighteen compounds were tested active, but they only activated Nrf2 moderately [13]. Further assay-guided separation of a crude extract led to the identification of MNG $\left(3.1 \mu \mathrm{g} / \mathrm{L}=7.7 \mathrm{nM}\right.$; Figure 1 ; MS and ${ }^{1} \mathrm{H}$ NMR: Figures S1 and S2) as a potent Nrf2 activator. Treatment of Nrf2-HepG2 stable cells with MNG resulted in a dose-dependent increase in ARE-dependent luciferase activity (Figure 2a). The induction of the reporter gene was enhanced about twofold at $5 \mu \mathrm{M}$ and 20 -fold at $80 \mu \mathrm{M}$ in the luciferase system. Next, we investigated the cytotoxicity of MNG against the EA.hy926 cells with the MTT assay (Figure 2b). No cellular toxicity of MNG was observed at concentrations of up to $80 \mu \mathrm{M}$ at $24 \mathrm{~h}$. Therefore, in this study, MNG was tested at concentrations between 5 and $80 \mu \mathrm{M}$ in the subsequent experiments.

(a)

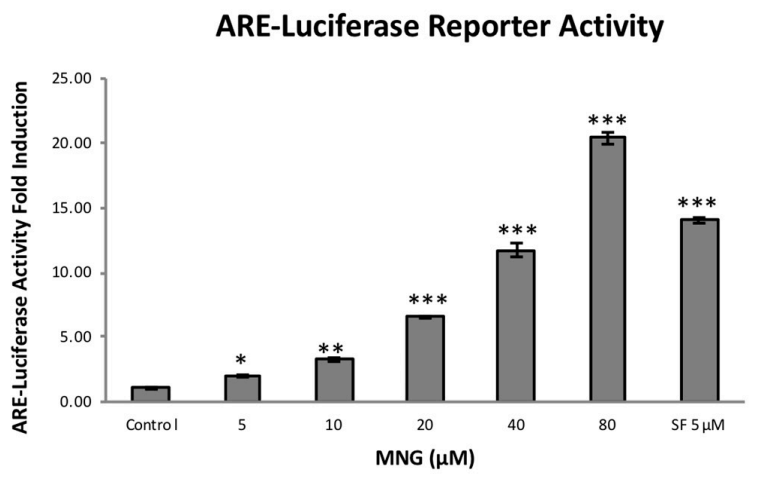

(b)

\section{EA.hy926 cells}

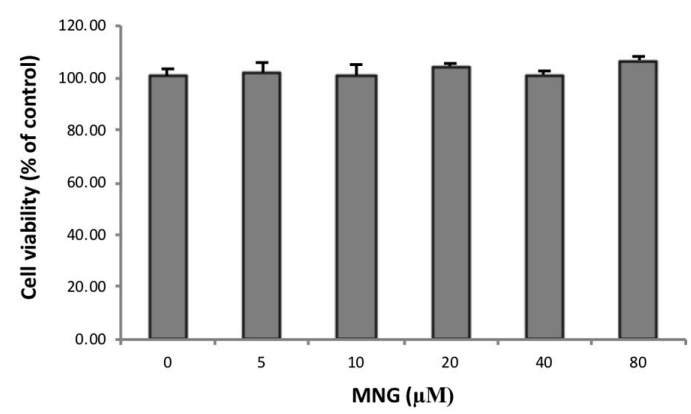

Figure 2. Nrf2 activation and cytotoxicity of MNG. (a) The effect of MNG on ARE-luciferase reporter activity in ARE reporter-HepG2 cells. Cells were seeded in 96-well plates at a density of $4 \times 10^{4}$ cells/well and incubated for $24 \mathrm{~h}$. The cells were further treated with 5, 10, 20, 40 and $80 \mu \mathrm{M}$ of MNG for additional $24 \mathrm{~h}$. The negative control cells were treated with $0.2 \%$ DMSO, and positive control cells were treated with $5 \mu \mathrm{M}$ SF. Luciferase activity was determined. (b) The cytotoxicity of MNG toward EA.hy926 cells. Cells were incubated with MNG at the indicated concentrations for $24 \mathrm{~h}$ and their viabilities were determined by MTT. The compound had no influence on cell viability at concentrations between 5 and $80 \mu \mathrm{M}$ for $24 \mathrm{~h}$. The data in the figure represent the mean \pm SEM of 3 independent experiments. ${ }^{*} p<0.05,{ }^{* *} p<0.01$ and ${ }^{* * *} p<0.001$ compared with the control group.

\subsection{MNG Clearly Increased Expression of Nrf2 and Its Target Genes in EA.hy926 Cells}

To investigate whether MNG could induce the expression of Nrf2-ARE transcriptional activity, we analyzed the effect of MNG on Nrf2 protein and mRNA expressions using Western blot and RT-qPCR, respectively. Similar to the luciferase activity, MNG upregulated the Nrf2 protein expression in a dose-dependent manner (Figure 3a). Since both HO-1 and NQO1 are typical downstream antioxidant enzymes mediated by Nrf2 [18], the effects of MNG on the protein and mRNA expression of HO-1 and NQO1 were also assessed. Results showed that MNG induced the HO-1 (Figure 3b,e) and NQO1 (Figure 3c,f) protein and mRNA expression in a dose-dependent manner. Similarly, expression of Nrf2, HO-1 and NQO1 was strongly induced by the positive control (SF). Western blot analysis was also performed to detect the expression of $\mathrm{Nrf} 2 / \mathrm{HO}-1$ protein as a function of time. The results demonstrated that the MNG treatment significantly increased HO-1 protein expression from $1 \mathrm{~h}$ to $24 \mathrm{~h}$ in a time-dependent manner (Figure $3 \mathrm{~h}$ ). On the other hand, the MNG 
treatment resulted in a time-dependent increase in Nrf2 protein expression from $2 \mathrm{~h}$ to 16 h. However, the Nrf2 protein expressions at 20 and $24 \mathrm{~h}$ treatment times were decreased (Figure 3g).

(a)

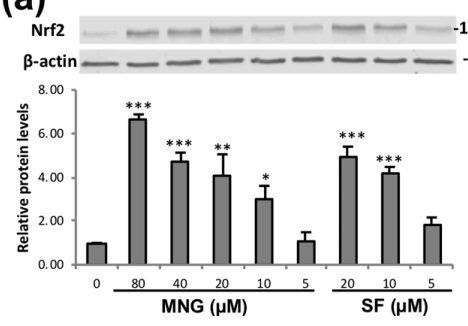

(d)

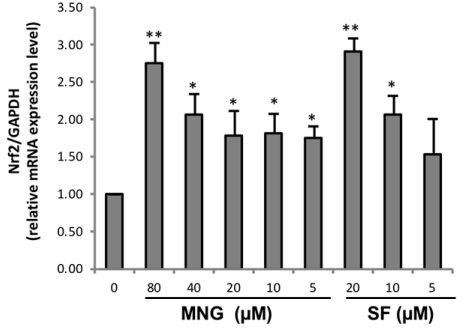

(g)

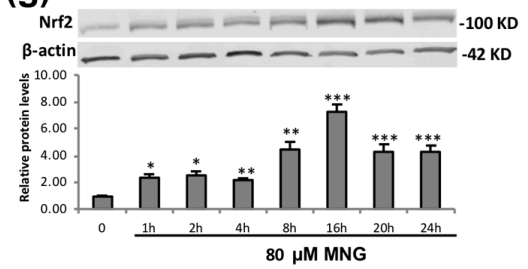

(b)

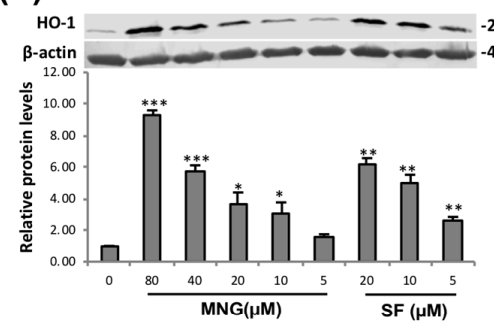

(e)

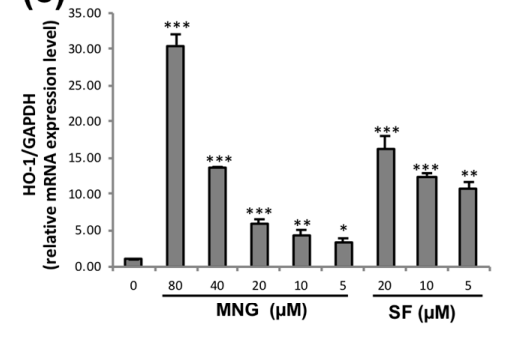

(h)

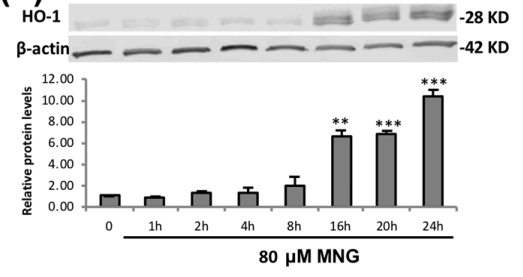

(c)

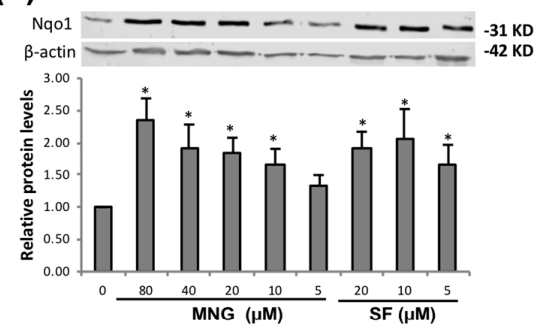

(f)

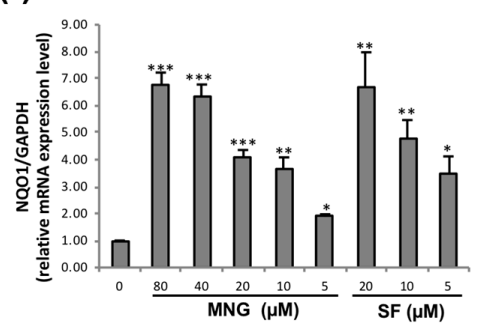

Figure 3. Enhanced expression of Nrf2, HO-1 and NQO1 by MNG in EA.hy926 cells in a dose-dependent manner. (a-c) The cells were treated for $24 \mathrm{~h}$ with MNG and SF at the indicated concentrations. The protein expression of Nrf2, HO-1 and NQO1 was analyzed by Western blot. An equal amount of protein from whole cell lysates was loaded and the $\beta$-actin protein level was considered as an internal control. SF was used as a positive control. (d-f) Total RNA was extracted from EA.hy926 cells treated as indicated. The mRNA expression of Nrf2, HO-1 and NQO1 was determined by real-time qPCR. SF was used as a positive control. (g,h) EA.hy926 cells were treated with $80 \mu \mathrm{M}$ MNG for the indicated durations. The Nrf2/HO-1 protein expression was analyzed by Western blot. The data in the figure represent the mean \pm SEM of 3 independent experiments. ${ }^{*} p<0.05,{ }^{* *} p<0.01$ and ${ }^{* * *} p<0.001$ compared with the control group.

\subsection{MNG Effectively Induced Nrf2 Nuclear Translocation in EA.hy926 Cells}

When exposed to oxidative stress or Nrf2 activators, a few reactive cysteine residues of Keap1 are modified to prevent Nrf2 from proteasome degradation, resulting in the accumulation of Nrf2 in cytosol, followed by rapid nuclear translocation of Nrf2 [19]. To further confirm whether Nrf2 stabilized by MNG was accumulated in the nucleus to stimulate Nrf2-mediated ARE transcription, we then assessed the effect of MNG on the Nrf2 activation via the nuclear enrichment of Nrf2 in EA.hy926 cells. MNG treatment improved the expression of nuclear Nrf2 remarkably, and the peak occurred at $20 \mathrm{~h}$ (Figure 4). At $24 \mathrm{~h}$ MNG still significantly enhanced Nrf2 nuclear translocation dose dependently with the strongest effect at $80 \mu \mathrm{M}$ (Figure 4). Fluorescence images from the Operetta imaging system clearly depicted the translocation of Nrf2 to nuclei in response to MNG (Figure 4a). The majority of Nrf2 protein in EA.hy926 cells was localized to nuclei, indicating the activation of the Nrf2 pathway (Figure 4a,b). Western blot analysis indicated that MNG treatment improved the expression of nuclear Nrf2 remarkably and increased Nrf2 abundance in the nuclei dose dependently (Figure 4c). The fidelity of the nuclear preparations was confirmed by Western blot against the nuclear membrane protein Histone $\mathrm{H} 3$. 


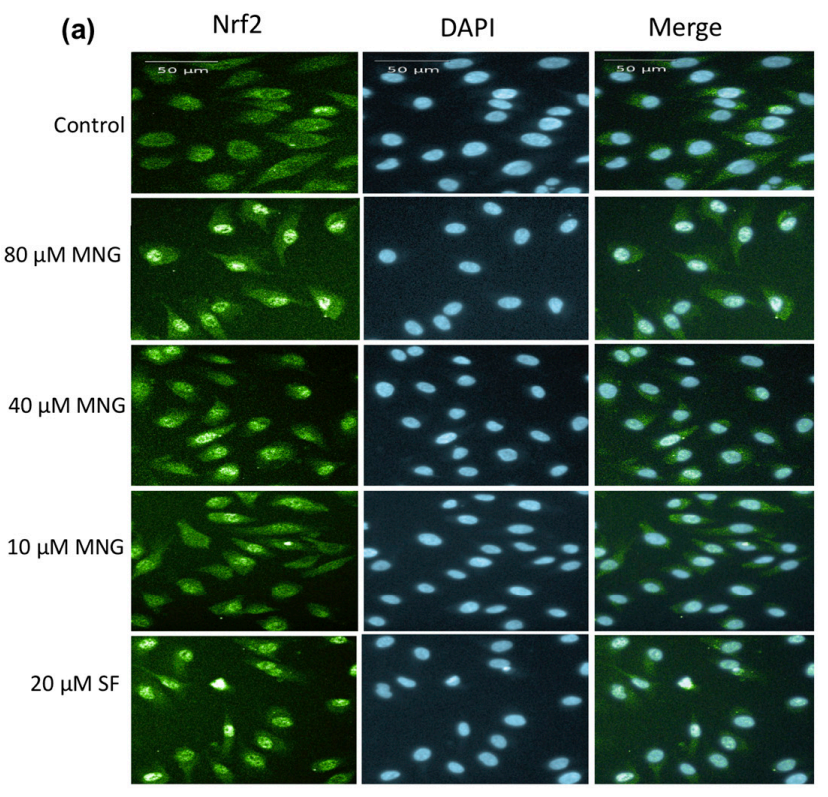

(b)

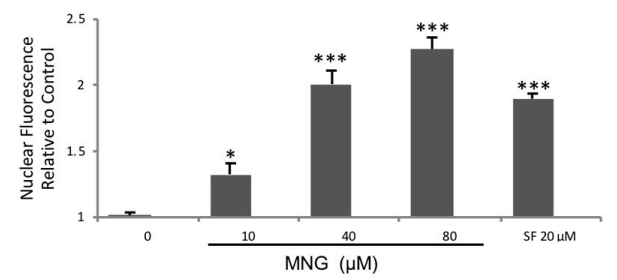

(c)

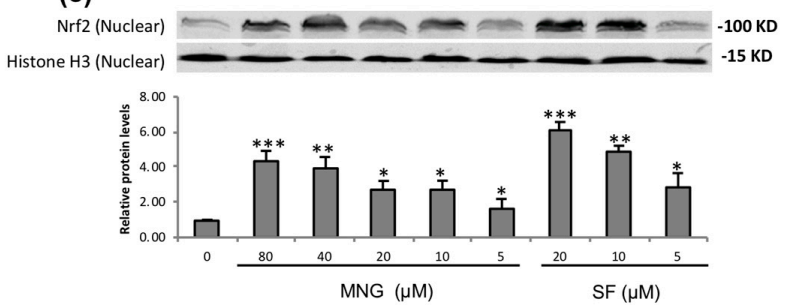

(d)

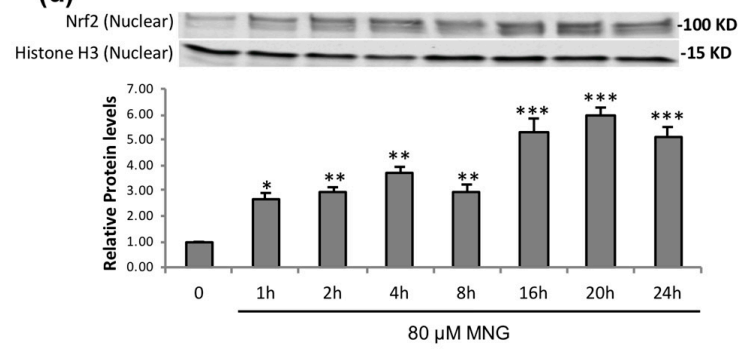

Figure 4. Effects of MNG on nuclear translocation of Nrf2 in EA.hy926 cells. (a) Representative images in EA.hy926 cells. Nuclei were stained by DAPI (blue) and transcription factors were stained by immunolabeled antibodies for Nrf2 (green). The fluorescent images were acquired by an Operetta high-content imaging system, using a $20 \times$ objective lens (Scale bar represents $50 \mu \mathrm{m}$ ). (b) Average relative nuclear fluorescence was quantified by the intensity of fluorescence from individual cells. (c) Cells were incubated with MNG and SF at the indicated concentrations for $24 \mathrm{~h}$. The protein expression of Nrf2 in nuclear extracts was examined by Western blot. Histone H3 was used as loading control for nuclear extracts. (d) EA.hy926 cells were treated with $80 \mu \mathrm{M}$ MNG for the indicated durations. The Nrf2 protein translocated into nuclei was analyzed by Western blot. The data in the figure represent the mean \pm SEM of 3 independent experiments. ${ }^{*} p<0.05,{ }^{* *} p<0.01$ and *** $p<0.001$ compared with the control group.

\subsection{MNG Protected EA.hy926 Cells against $\mathrm{H}_{2} \mathrm{O}_{2}$-Induced Cell Death}

Low $\mathrm{H}_{2} \mathrm{O}_{2}$ concentration promotes the beneficial proliferation, but high $\mathrm{H}_{2} \mathrm{O}_{2}$ concentration is deleterious. $\mathrm{H}_{2} \mathrm{O}_{2}$ is a type of ROS that could cross cell membranes and initiate oxidative stress [20]. $\mathrm{H}_{2} \mathrm{O}_{2}$ is also a well-known cell damaging agent and has been used widely in numerous in vitro oxidative stress experiments [21]. To investigate the protection of MNG against cell death induced by ROS, we utilized $\mathrm{H}_{2} \mathrm{O}_{2}$ to induce oxidative injury in EA.hy926 cells in this study (Figure 5). There was a concentration-dependent decrease in cell viability after treatment with $\mathrm{H}_{2} \mathrm{O}_{2}$ (Figure 5 a). Compared with cell viability in the control group, $\mathrm{H}_{2} \mathrm{O}_{2}$ at $550 \mu \mathrm{M}$ caused about $50 \%$ decrease in cell viability. Thus, $550 \mu \mathrm{M}$ $\mathrm{H}_{2} \mathrm{O}_{2}$ was selected for subsequent assays. MNG pretreatment at 5-80 $\mu \mathrm{M}$ attenuated $\mathrm{H}_{2} \mathrm{O}_{2}$-induced cell death in a dose-dependent manner (Figure $5 b$ ). To evaluate the cytoprotective effect of MNG, morphologic changes of EA.hy926 cells were measured by using Hoechst 33342/PI double fluorescent staining [22]. Compared with the groups untreated with $\mathrm{H}_{2} \mathrm{O}_{2}$ (Figure 5(c1,c2), control and $80 \mu \mathrm{M} M N G$, respectively), cells exhibited the typical features of cell death after treatment with $550 \mu \mathrm{M} \mathrm{H}_{2} \mathrm{O}_{2}$ (Figure 5(c3)). However, pretreatment with MNG $(5,10,20,40$ and $80 \mu \mathrm{M})$ could effectively protect EA.hy926 cells against $\mathrm{H}_{2} \mathrm{O}_{2}$-induced cell death (Figure 5(c4-c8)). 
(a)

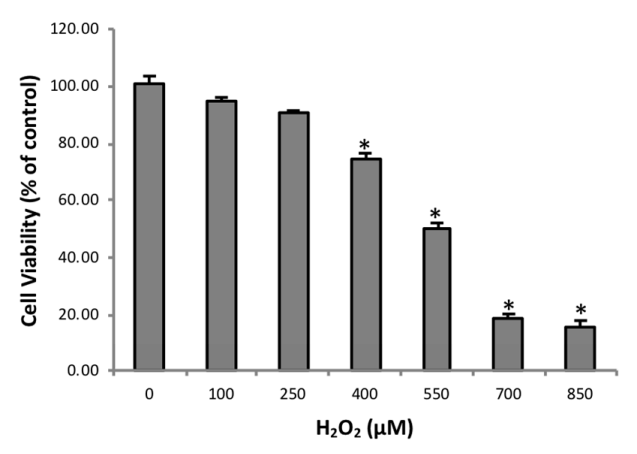

(c)
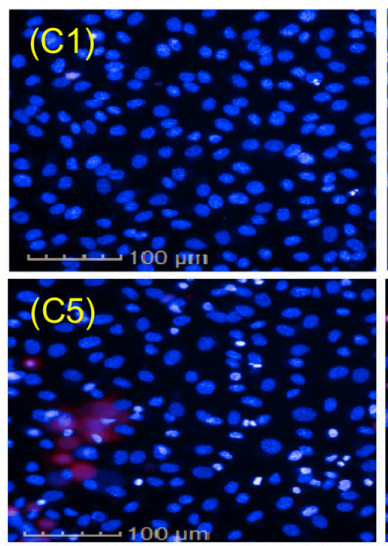

(b)

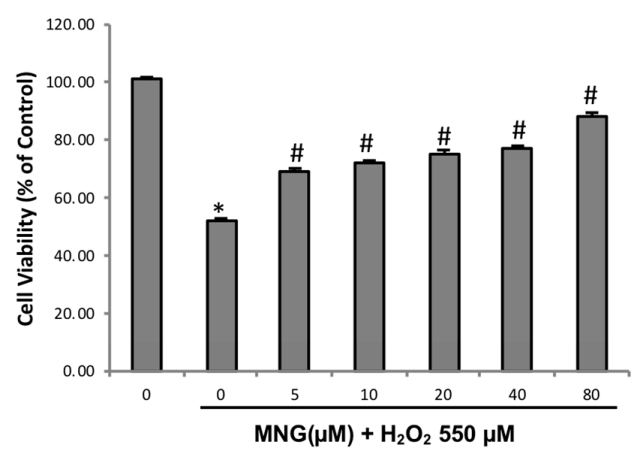

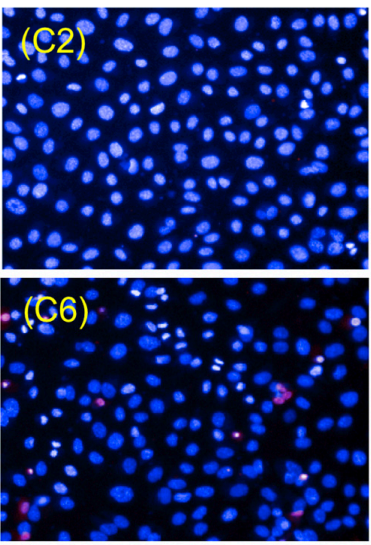

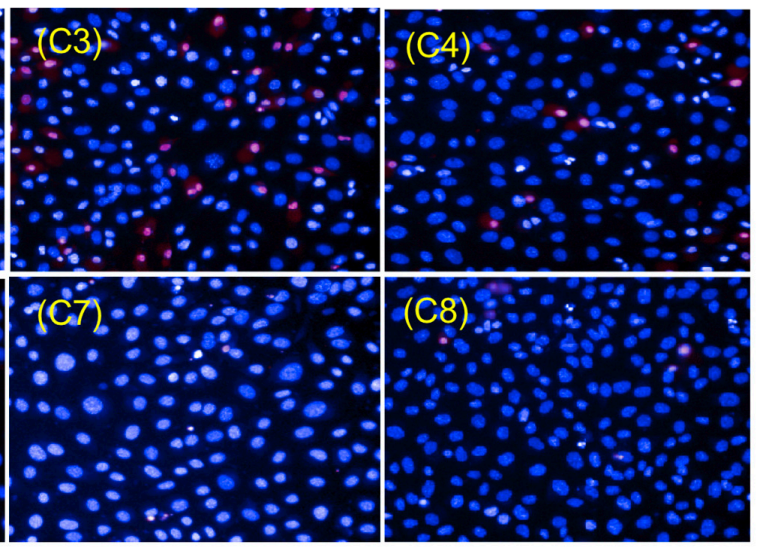

Figure 5. Protection of EA.hy 926 cells by $\mathrm{MNG}$ against $\mathrm{H}_{2} \mathrm{O}_{2}$-induced cell death. (a) Cells were treated with $550 \mu \mathrm{M} \mathrm{H} \mathrm{H}_{2} \mathrm{O}_{2}$ for $6 \mathrm{~h}$. $\mathrm{H}_{2} \mathrm{O}_{2}$ caused a concentration-dependent reduction of cell viability in EA.hy926 cells. (b) Cells were pretreated with 0-80 $\mu \mathrm{M}$ MNG for $24 \mathrm{~h}$, followed by incubation with or without $550 \mu \mathrm{M} \mathrm{H}_{2} \mathrm{O}_{2}$ for $6 \mathrm{~h}$. Cytoprotection of MNG against $\mathrm{H}_{2} \mathrm{O}_{2}$-induced injury in EA.hy926 cells showed a dose-dependent enhancement from $5 \mu \mathrm{M}$ to $80 \mu \mathrm{M}$. Cell viability was determined by using the MTT assay. ${ }^{*} p<0.05$ vs. control group, ${ }^{\#} p<0.05$ vs. $550 \mu \mathrm{M} \mathrm{H}_{2} \mathrm{O}_{2}$ group. Data are the means \pm SEM of 3 independent experiments. (c) Cell death was determined by using Hoechst 33,342 and PI double fluorescent staining C1: control; C2: $80 \mu \mathrm{M}$ MNG; C3: $550 \mu \mathrm{M} \mathrm{H}_{2} \mathrm{O}_{2}$; C4-C8: 5, 10, 20, 40, $80 \mu \mathrm{M} \mathrm{MNG}+550 \mu \mathrm{M} \mathrm{H}_{2} \mathrm{O}_{2}$; scale bars represent $100 \mu \mathrm{m}$.

\subsection{Inhibition of ROS Production by MNG}

Intracellular ROS is an indicator reflecting the level of oxidative stress directly [23]. To investigate the inhibition of ROS production, we investigated the inhibitory effect of MNG on the intracellular ROS generated by $\mathrm{H}_{2} \mathrm{O}_{2}$. Intracellular ROS levels were measured by using a fluorescence microplate reader and an Operetta high-content imaging system after staining with a fluorescent probe, DCFH-DA (Figure 6). Similar to the negative control (Figure 6a, 1st panel), MNG alone did not generate ROS (Figure 6a, 2nd panel). $\mathrm{H}_{2} \mathrm{O}_{2}$ treatment induced a massive production of ROS (Figure 6a, 3rd panel), which caused oxidative stress. However, pretreatment with $\mathrm{MNG}$ notably prevented the $\mathrm{H}_{2} \mathrm{O}_{2}$-induced ROS generation in a dose-dependent manner (Figure 6a, panels 4-8). The quantitative intensities of DCFH-DA in various groups measured by using a fluorescence microplate reader are shown in Figure 6b. When stimulated with $\mathrm{H}_{2} \mathrm{O}_{2}$, the intracellular ROS level in EA.hy926 cells increased rapidly. MNG significantly suppressed ROS production in a dose-dependent manner (Figure 6b). 
(a)

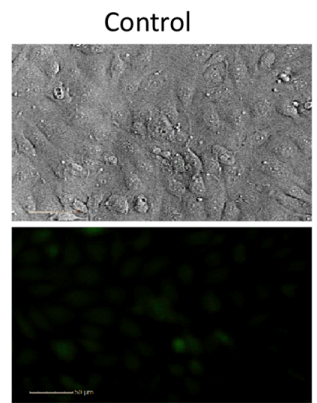

$20 \mu \mathrm{M} \mathrm{MNG}+\mathrm{H}_{2} \mathrm{O}_{2}$
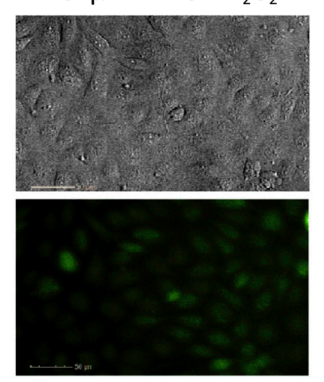

$80 \mu \mathrm{M}$ MNG
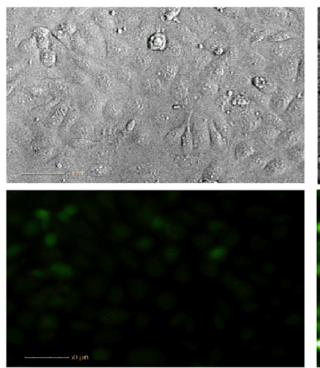

$10 \mu \mathrm{M} \mathrm{MNG}+\mathrm{H}_{2} \mathrm{O}_{2}$
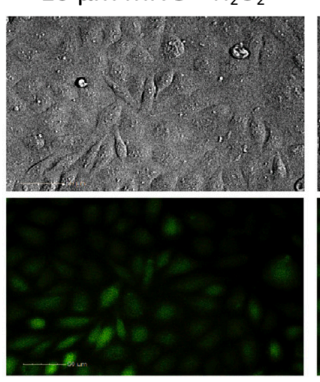

$550 \mu \mathrm{M} \mathrm{H}_{2} \mathrm{O}_{2}$

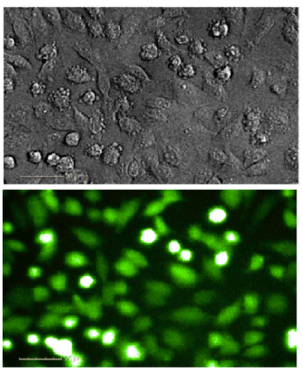

$5 \mu \mathrm{M} \mathrm{MNG}+\mathrm{H}_{2} \mathrm{O}_{2}$

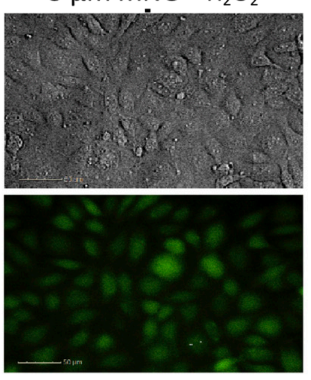

$80 \mu \mathrm{M} \mathrm{MNG}+\mathrm{H}_{2} \mathrm{O}_{2}$
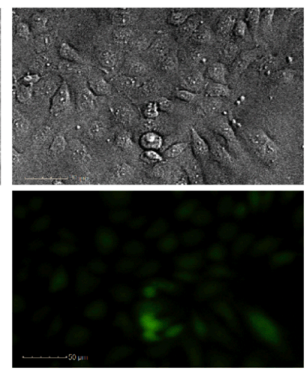

(b)

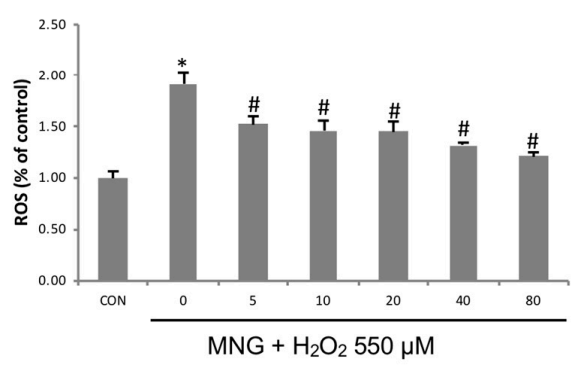

Figure 6. MNG reduced the intracellular ROS generation in EA.hy926 cells. (a) Representative images of ROS in EA.hy926 cells were detected by DCFH-DA using the Operetta high content image: vehicle-treated control cells; cells only treated

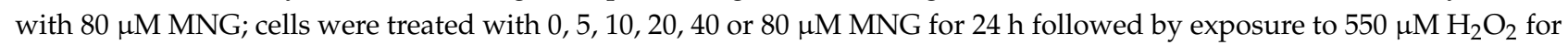
another $6 \mathrm{~h}$ (Scale bars represent $50 \mu \mathrm{m}$ ). (b) The levels of intracellular ROS were detected by DCFH-DA using a fluorescence microplate reader. EA.hy926 cells were pretreated with MNG for $24 \mathrm{~h}$ at the indicated doses $(0,5,10,20,40$ and $80 \mu \mathrm{M})$ before treatment with $550 \mu \mathrm{M} \mathrm{H}_{2} \mathrm{O}_{2}$ for $6 \mathrm{~h}$ and then incubated with $10 \mu \mathrm{M}$ DCFH-DA for $30 \mathrm{~min}$. ${ }^{*} p<0.05$ vs. control group, ${ }^{\#} p<0.05$ vs. $550 \mu \mathrm{M} \mathrm{H}_{2} \mathrm{O}_{2}$ group. Data are the means $\pm \mathrm{SEM}$ of 3 independent experiments.

\subsection{Nrf2 siRNA Attenuated the MNG-Mediated Cytoprotective Effect and Induction of HO-1 and NQO1}

The silencing of Nrf2 using siRNA can markedly reduce the Nrf2 level and AREdriven activity and has been used extensively to study the action mechanisms of Nrf2 activators [24]. To further verify the role of Nrf2 in regulating the expression of its target proteins by MNG, we evaluated the effect of Nrf2 siRNA on the MNG-mediated protective activity against oxidative damage in EA.hy926 cells (Figure 7). Nrf2 siRNA-treated groups showed lower levels of Nrf2 as compared to NC siRNA transfected and non-transfected control cells (Figure 7a). Then, Western blot was employed to further examine the impact of Nrf2 silencing on MNG-mediated induction of HO-1 and NQO1. As shown in Figure 7b,c, Nrf2 silencing significantly suppressed the MNG-induced upregulation of $\mathrm{HO}-1$ and NQO1. An MTT assay revealed that the cytoprotective effects of MNG against the $\mathrm{H}_{2} \mathrm{O}_{2}$ insult were significantly reduced by siRNA-induced knockdown of Nrf2 (Figure 7d). 
(a)

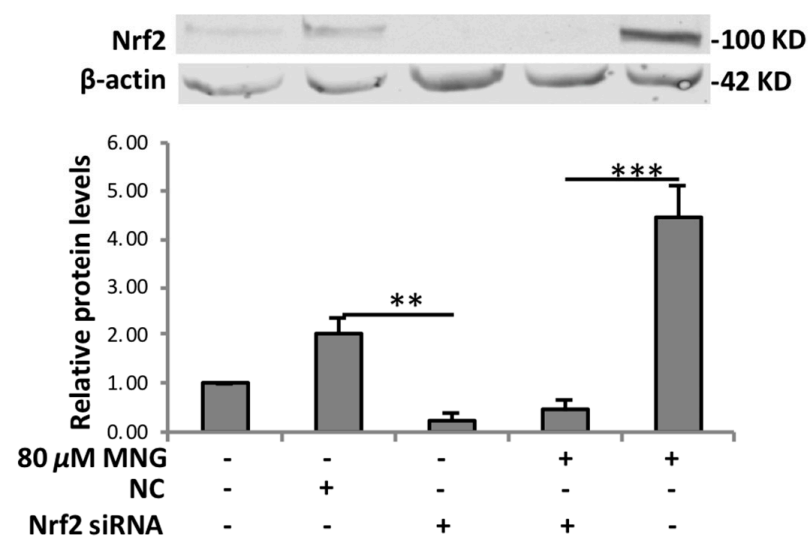

(c)

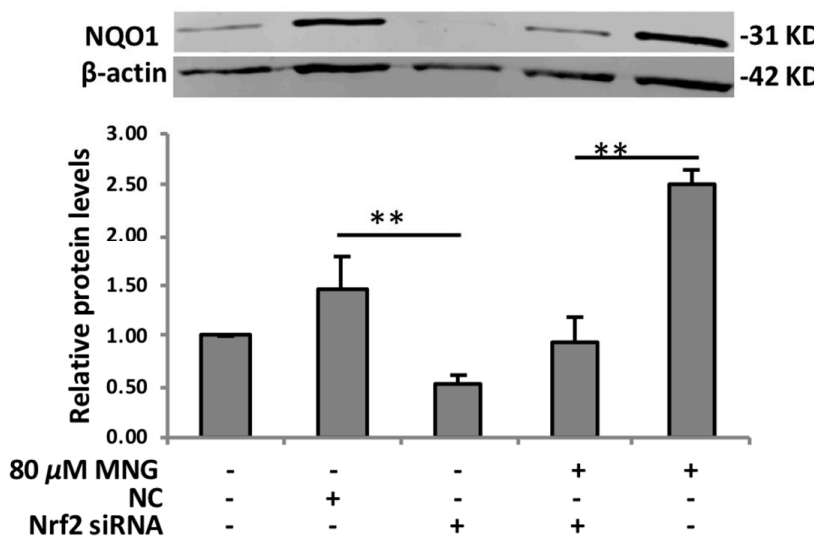

(b)

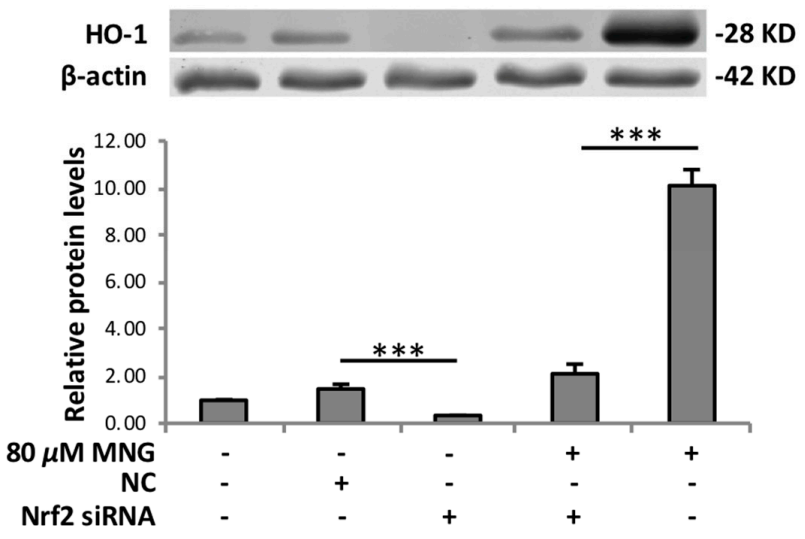

(d)

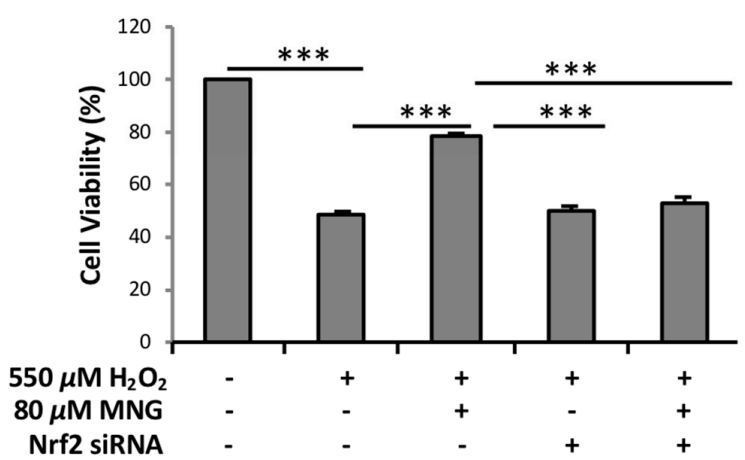

Figure 7. Nrf2 silencing attenuated MNG-mediated cytoprotective effect and induction of HO-1 and NQO1. (a-c) The cells were transfected with Nrf2 siRNA or NC siRNA, then incubated with or without $80 \mu \mathrm{M}$ MNG for 24 h, protein expression levels of Nrf2, HO-1 and NQO1 were detected by Western blot. (d) Nrf2 silencing reduced the cytoprotective effects of 80 $\mu \mathrm{M}$ MNG on $\mathrm{H}_{2} \mathrm{O}_{2}$-induced cell damage. The cells were transfected with Nrf2 siRNA or NC siRNA, then incubated with or without $80 \mu \mathrm{M}$ MNG for $24 \mathrm{~h}$, followed by $550 \mu \mathrm{M} \mathrm{H}_{2} \mathrm{O}_{2}$ for a further $6 \mathrm{~h}$. All data in the figure are presented as means \pm SEM of 3 independent experiments. ${ }^{* *} p<0.01,{ }^{* * *} p<0.001$ compared to the indicated group.

\subsection{PI3K/AKT Regulated MNG-Induced Nrf2/HO-1 Expression}

Studies have demonstrated that the PI3K/Akt pathway acts as an important upstream regulator of Nrf2/HO-1 expression [25], and it is essential in activating the Nrf2-ARE pathway in many types of cells $[26,27]$. Hence, next, we investigated the possible role of the PI3K/Akt pathway in our study. Treatment with MNG significantly upregulated phosphorylation of Akt in EA.hy926 cells in a dose-dependent manner (Figure 8a). MNG treatment notably enhanced Akt phosphorylation after treatment in a time-dependent manner (Figure 8b), but not the total Akt protein level, suggesting that the PI3K/Akt pathway played a key role in regulating Nrf2-ARE-dependent protection of MNG in EA.hy926 cells. 
(a)

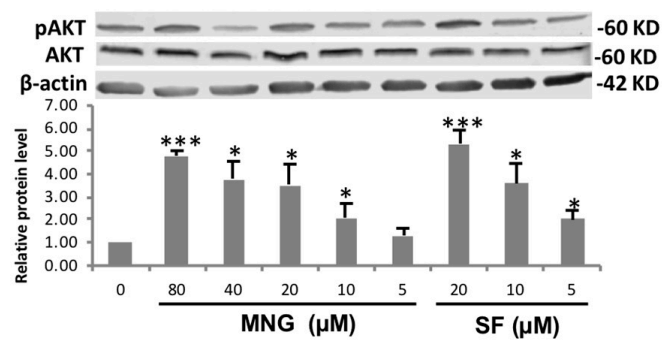

(b)
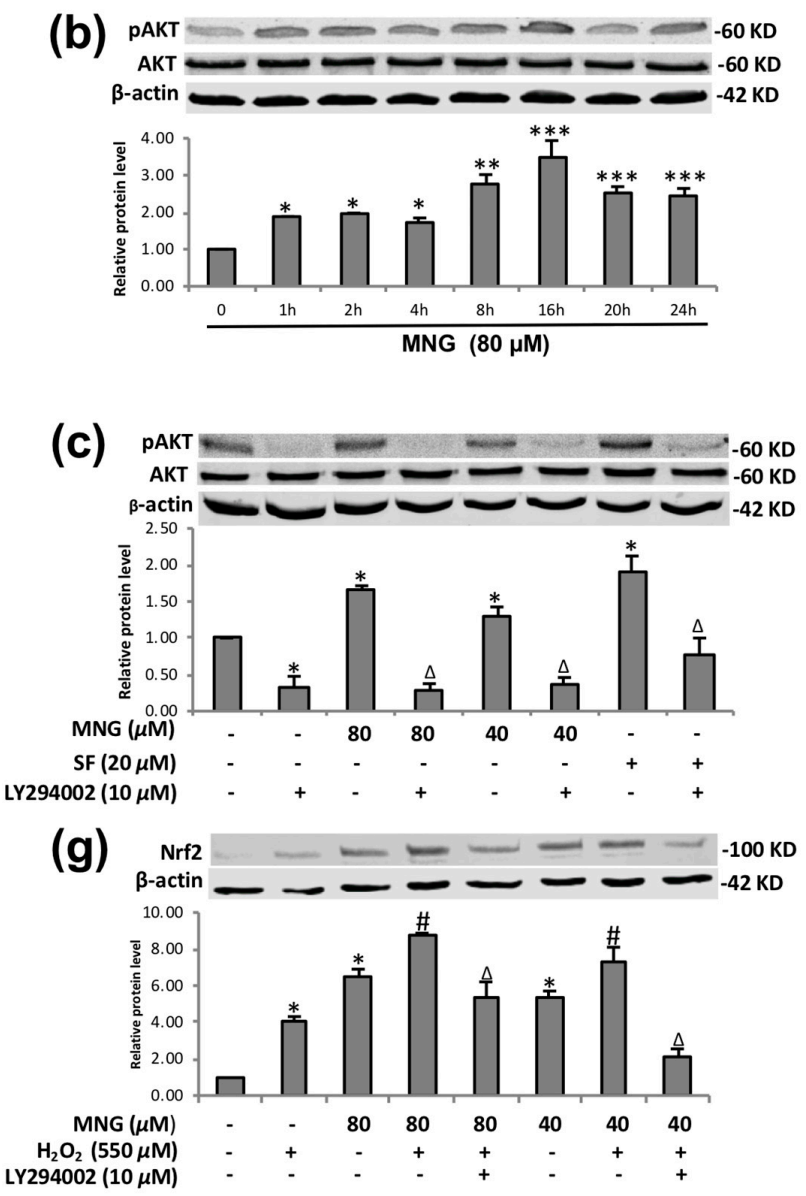
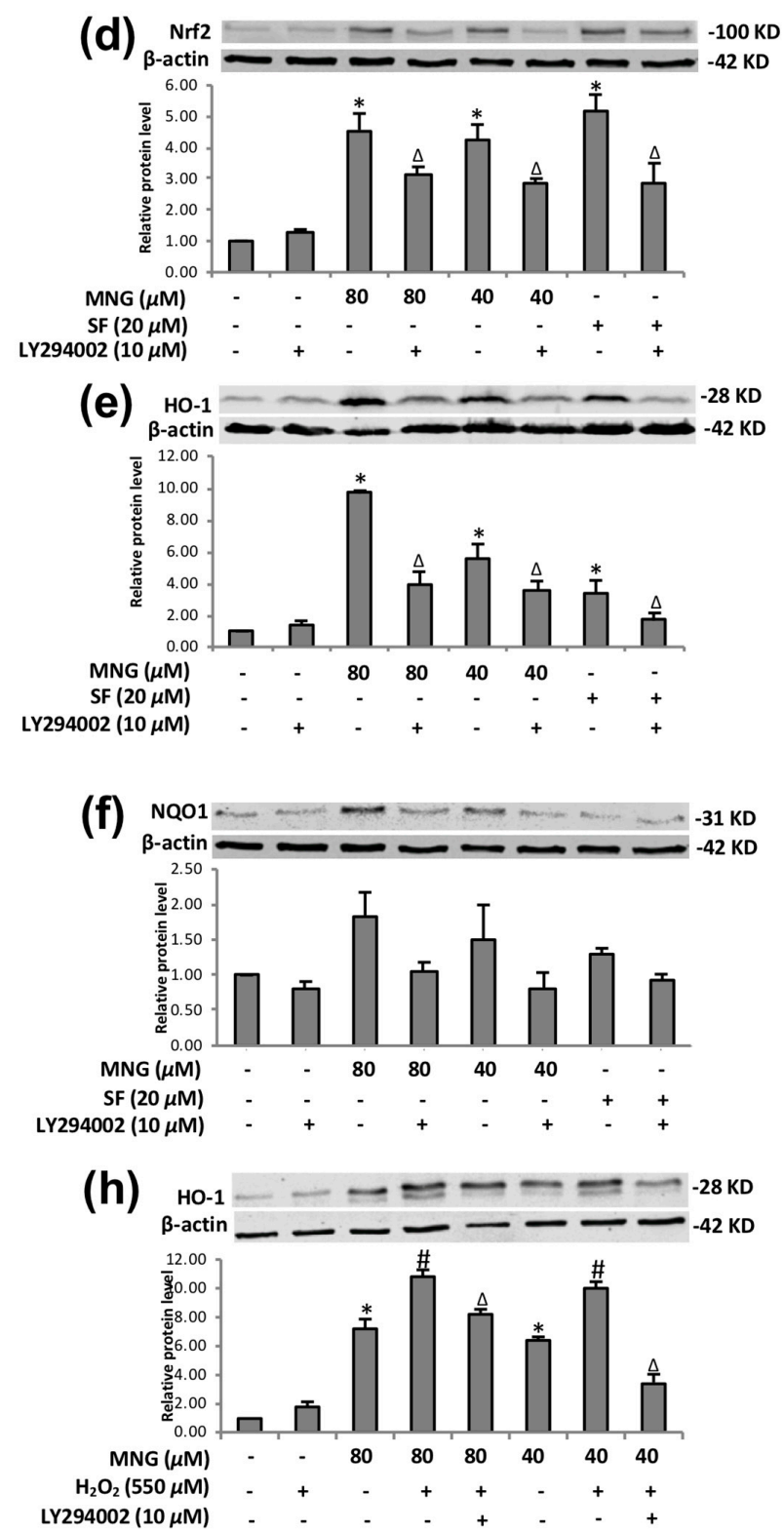

Figure 8. MNG stimulated Nrf2/HO-1 partially via the PI3K/Akt pathway in EA.hy 926 cells. (a) EA.hy926 cells were treated with $0-80 \mu \mathrm{M}$ MNG for $24 \mathrm{~h}$, and the protein levels of p-Akt were determined by using Western blot. (b) Cells were treated with $80 \mu \mathrm{M}$ MNG for various time periods, and the protein levels of p-Akt were determined by using Western blot. (c-f). After preincubation with $10 \mu \mathrm{M}$ LY294002 for $2 \mathrm{~h}$, cells were cotreated with 40, $80 \mu \mathrm{M}$ MNG and $20 \mu \mathrm{M}$ SF for an additional $24 \mathrm{~h}$, and the protein levels of p-Akt, Akt, Nrf2, HO-1 and NQO1 were then detected by using Western blot. ${ }^{*} p<0.05,{ }^{* *} p<0.01,{ }^{* * *} p<0.001$ vs. control group, ${ }^{\Delta} p<0.05$ vs. $40,80 \mu \mathrm{M} \mathrm{MNG}$ or $20 \mu \mathrm{M} \mathrm{SF}$. (g,h) After preincubation with $10 \mu \mathrm{M}$ LY294002 and 40 or $80 \mu \mathrm{M}$ MNG for $24 \mathrm{~h}$, cells were cotreated with $550 \mu \mathrm{M} \mathrm{H}_{2} \mathrm{O}_{2}$ for an additional $6 \mathrm{~h}$; the protein levels of Nrf2 and HO-1 were then detected by using Western blot. ${ }^{*} p<0.05$ vs. control group, ${ }^{\#} p<0.05$ vs. $550 \mu \mathrm{M} \mathrm{H}_{2} \mathrm{O}_{2}$ group, ${ }^{\Delta} p<0.05$ vs. $40,80 \mu \mathrm{M}$ MNG $+550 \mu \mathrm{M} \mathrm{H}_{2} \mathrm{O}_{2}$ group. Data are the means $\pm \mathrm{SEM}$ of 3 independent experiments.

To further reveal the mechanism, we used LY294002 (a PI3K/Akt inhibitor) to investigate the effect of MNG on the PI3K pathway (Figure 8c-h). The results showed that Akt phosphorylation after MNG treatment was significantly inhibited by LY294002 (Figure 8c), which also attenuated, although did not completely abolish, the MNG-induced Nrf2, HO-1 and NQO-1 activation (Figures $8 \mathrm{~d}, 8 \mathrm{e}$ and $8 \mathrm{f}$, respectively).

Furthermore, after preincubation with LY294002 and MNG, EA.hy926 cells were treated with $\mathrm{H}_{2} \mathrm{O}_{2}$. The Western blot results of $\mathrm{Nrf} 2$ and $\mathrm{HO}-1$ protein expression showed 
that LY294002 attenuated the Nrf2 and HO-1 expression of EA.hy926 cells treated by MNG and $\mathrm{H}_{2} \mathrm{O}_{2}$, although not completely blocking the Nrf2 and HO-1 expression. (Figure 8g,h). LY294002 had no obvious inhibitory effect on the NQO-1 expression of EA.hy926 cells treated by $\mathrm{MNG}$ and $\mathrm{H}_{2} \mathrm{O}_{2}$ in the experimental setting. These findings further confirmed that to a certain degree, the PI3K/Akt pathway is implicated in the activation of Nrf2/HO-1 by MNG in EA.hy926 cells.

\section{Discussion}

A SciFinder search on June 01, 2021 revealed that there were 117 reports on MNG (CAS Registry Number 94367-42-7) (Figure 1, Figures S1 and S2). MNG was evaluated for its protection of PC12 cells from L-glutamate-induced toxicity, but it was inactive [16]. The inhibitory activity of MNG on LPS-stimulated proinflammatory cytokine production in bone marrow-derived dendritic cells was investigated [28]. The antiaging effect of a formulation containing MNG was also explored [29]. However, none of these 117 publications of MNG was related to Nrf2, indicating that the known compound MNG is a new Nrf2 activator. At the same concentration, SF was more potent than MNG in the ARE-luciferase assay (Figure 2a). However, a further MTT assay showed that MNG did not demonstrate any cytotoxicity against EA.hy 926 cells at $500 \mu \mathrm{M}$ after $24 \mathrm{~h}$, while SF showed certain cytotoxicity at $62.5 \mu \mathrm{M}$ and killed more than half of the EA.hy926 cells at $250 \mu \mathrm{M}$ after $24 \mathrm{~h}$ (Figure S3), indicating MNG's superiority to SF when comparing their cytotoxicity, although SF was a more potent Nrf2 activator than MNG. According to the concentration of MNG in the product $(7.7 \mathrm{nM})$, the doses we applied in our experiments were much higher than the content of MNG in the beverage. However, our aims were to investigate the potential mechanisms of action of MNG in protecting EA.hy926 cells against $\mathrm{H}_{2} \mathrm{O}_{2}$-induced oxidative stress through the activation of the $\mathrm{Nrf} 2 / \mathrm{HO}-1$, and to explore the possibility of using MNG as a food additive.

It is interesting that MNG did not increase the level of Nrf2 mRNA at 10 and $20 \mu \mathrm{M}$ when compared with that at $5 \mu \mathrm{M}$ (Figure 3d), suggesting that MNG does not activate the Nrf2 pathway constitutively. However, MNG upregulated the Nrf2 mRNA expression slightly at $40 \mu \mathrm{M}$ and much more at $80 \mu \mathrm{M}$ (Figure 3d), which might be due to an increased cell reproduction as evidenced by the MTT assay results (Figure S3). When the EA.hy926 cells were treated with MNG, the activation of the Nrf2 protein decreased after $16 \mathrm{~h}$ (Figure 3g), suggesting that the physiological response to activate the Nrf2 pathway was already saturated under this condition. The phenomenon was not uncommon [30]. It is possible that Nrf2 reached its maximal activation within $16 \mathrm{~h}$, which might be associated with an overall commitment to Nrf2 activation of the majority of the cells by MNG. After $16 \mathrm{~h}$, probably there was not much remaining Keap 1 to be targeted by the electrophiles, resulting in decreased accumulation of Nrf2 in nuclei [31]. It is worth mentioning that there was no significant enhancement of NQO1 protein within $24 \mathrm{~h}$ (Figure 3a-c) when compared with Nrf2 and HO-1, suggesting that it might take a longer time for MNG to increase the NQO1 protein in EA.hy926 cells. However, MNG enhanced the expression of NQO-1 in a dose-dependent manner (Figure 3c). Nevertheless, the results strongly support the hypothesis that MNG could enhance the cytoprotective effect and antioxidant response through activating Nrf2 and then inducing the expression of HO-1 and NQO1 expression.

The well-known Nrf2 activator, resveratrol induces the translocation of Nrf2 to nuclei in different types of cell lines [32]. As an electrophile, SF (an Nrf2 activator, widely used as a positive control) also enables Nrf2 to escape from Keap1-dependent degradation, which induces the nuclear translocation of Nrf2 followed by the activation of phase 2 enzymes in EA.hy926 cells [33]. The results were in agreement with our study (Figure 4), in which both SF- (positive control) and MNG-induced nuclear translocation of Nrf2 was confirmed by Operetta imaging and Western blot. A time course study showed that there was an accumulation of Nrf2 in the nucleus shortly after MNG treatment, but that there was more Nrf2 nuclear translocation at 16-24 h (Figure $4 \mathrm{~d}$ and Figure S4). The time course pattern of the Nrf2 nuclear translocation after MNG treatment was similar to the time-dependent 
pattern of the Nrf2 protein expression as shown in Figure 3g. Hence, MNG might stabilize Nrf2 protein in the cytosol and then enhance its translocation to the nuclei.

Many Nrf2 activators, such as resveratrol, showed an inhibitory effect against the harmful effect of ROS [34]. Our results (Figure 5) demonstrated that MNG could also inhibit the deleterious effect of ROS, exerting its cytoprotective activity by blocking cell death and recovering cell viability in oxidative-stress-stimulated EA.hy926 cells, which was further supported by the experimental results as shown in Figure 6.

It was reported that Nrf2 activators could suppress the production of ROS. For example, pterostilbene (a 3,5-O-dimethylated resveratrol) could restore vascular redox balance, which was evidenced by decreased $\mathrm{H}_{2} \mathrm{O}_{2}$ production [35]. MNG could also inhibit the production of $\mathrm{H}_{2} \mathrm{O}_{2}$-induced intracellular ROS in EA.hy926 cells, indicating that MNG had an antioxidative effect. Meanwhile, MNG alone could not induce the oxidative stress in EA.hy926 cells because the MNG treatment alone had no effect on the level of intracellular ROS (Figure 6a, 2nd panel). The data strongly suggested that MNG could enhance the defensive system of endogenous antioxidation, which has been proven to be the frontline of defense against oxidative stress [36,37]. The result was further confirmed by the abolishment of the MNG's protection against $\mathrm{H}_{2} \mathrm{O}_{2}$ insult by Nrf2 siRNA (Figure 7).

MNG could protect EA.hy926 cells from $\mathrm{H}_{2} \mathrm{O}_{2}$ damage. However, when the Nrf2 expression was downregulated by siRNA, the EA.hy926 cells were susceptible to $\mathrm{H}_{2} \mathrm{O}_{2}$ insult both in the presence and absence of MNG (Figure 7d), indicating that MNG exerted its protective effect against $\mathrm{H}_{2} \mathrm{O}_{2}$ through the activation of Nrf2; otherwise, siRNA could not block the cytoprotective effect of MNG against $\mathrm{H}_{2} \mathrm{O}_{2}$ insult. These results suggest that $\mathrm{Nrf2}$ is an essential factor for the MNG-induced ARE transcriptional activity, including the expression of Nrf2's downstream genes (for examples, HO-1 and NQO1). Clearly, the MNG-induced cytoprotective effect against $\mathrm{H}_{2} \mathrm{O}_{2}$ was mediated by the activation of Nrf2 in EA.hy926 cells.

The pAkt/Akt ratio in Figure 8b exhibited a broad bell-shape [38], and reached its maximal activation by MNG within $16 \mathrm{~h}$. This might also be associated with an overall commitment to Akt activation of the majority of the cells by MNG. After $16 \mathrm{~h}$, probably there was not much remaining Akt to be phosphorylated, resulting in the decreased expression of pAkt. The results suggested that MNG could enhance the cytoprotective effect and antioxidant response through activating PI3K/Akt pathway, at least to a certain extent. If the activation of Nrf2 by MNG were regulated solely through the activation of the PI3K/Akt pathway, LY294002 should be able to completely block the activation of Nrf2, HO-1 and NQO1 by MNG (Figure 8d-f). Therefore, we concluded that PI3K/Akt pathway is important for the cytoprotection of MNG, and the pathway is partially involved in the activation of the Nrf2/HO-1 (NQO1) pathways by MNG, which was further supported by the partial abolishment of the MNG's protection against $\mathrm{H}_{2} \mathrm{O}_{2}$-induced insult by LY294002 as shown in Figure 8g,h. It is worth mentioning that under certain concentrations, $\mathrm{H}_{2} \mathrm{O}_{2}$ can increase the Nrf2 protein through the de novo synthesis of Nrf2, as evidenced in Figure $8 \mathrm{~g}, \mathrm{~h}$, but a high concentration of $\mathrm{H}_{2} \mathrm{O}_{2}$ is toxic as shown in Figure $5 \mathrm{a}$.

Taken together, our results show for the first time that the new Nrf2 activator MNG produced by A. membranaceus and isolated from Jing liqueur could attenuate the $\mathrm{H}_{2} \mathrm{O}_{2}$ induced cell death and oxidative stress in EA.hy926 cells, which may be involved in the activation of the Nrf2/HO- 1 and partially the PI3K/Akt pathways. Our results may also provide certain scientific support to the use of MNG as a food additive. Perhaps other signaling factors (for example, p38, MAPK, JNK, and GSK-3 $\beta$ ) are involved in the Nrf2 expression induced by MNG, which are worthy of further investigation. It is also worth carrying out an in vivo study, investigating the effects and mechanisms of MNG on the other types of cells, such as human neuroblastic and beta cells and so on, and studying its preventive effects on chronic diseases, such as cancer, Alzeimer's, diabetic and cardiovascular diseases. 


\section{Materials and Methods}

\subsection{Materials}

TRIzol reagent (\#T9424), radioimmunoprecipitation assay buffer (RIPA buffer, \#R0278) and Tris-buffered saline containing 0.1\% Tween-20 (TBST) were obtained from Sigma (St. Louis, MO, USA). Primary antibodies against Nrf2 (\#ab62352) and NQO1 (\#ab34173) were purchased from Abcam (Cambridge, MA, USA). HO-1 (\#5853S), p-Akt (\#4060S), Akt (\#4691S), $\beta$-actin (\#3700S), and Histone H3 (\#4499S) were purchased from Cell Signaling Technology (Danvers, MA, USA). Second antibody IRDye 680RD goat anti-mouse IgG (\#926-68070) and IRDye 800CW goat anti-rabbit IgG (\#926-32211) were purchased from LI-COR, Inc. (Lincoln, NE, USA). NE-PER Nuclear and Cytoplasmic Extraction Kit (\#78835) and Pierce BCA Protein Assay Kit (\#23227) were purchased from Thermo Fisher Scientific (Hanover Park, IL, USA). Nitrocellulose membrane, iTag universal SYBR green supermix (\#1725124) and iScript cDNA synthesis kit (\#1708891) were obtained from Bio-Rad (Hercules, CA, USA). Nrf2 Antioxidant Pathway ARE Reporter-HepG2 cell line (\#Q16236) was purchased from BPS Bioscience (San Diego, CA, USA). EA.hy926 cells (\#83-0020) were obtained from the UNC, Lineberger Comprehensive Cancer Center (Chapel Hill, NC, USA). Eagle's minimum essential medium (EMEM) and Dulbecco's Modified Eagle Medium (DMEM) were bought from Corning (New York, NY, USA). Fetal bovine serum (FBS) was purchased from Invitrogen (Waltham, MA, USA). RNeasy Mini Kit (\#74106) was bought from Qiagen (Hilden, Germany). Small interference RNAs (siRNA) against Nrf2 (siNrf2, \#sc-37030) as well as control-siRNA (c-siRNA, \#sc-37007) were purchased from Cruz Biotechnology (Santa Cruz, CA, USA).

\subsection{Chemicals}

Compounds were dissolved as a $40 \mathrm{mM}$ stock solution in dimethyl sulfoxide (DMSO), stored at $-20{ }^{\circ} \mathrm{C}$, and diluted to test concentrations with culture medium immediately prior to the experiment. The final concentration of DMSO in the culture medium was less than $0.2 \%$. Hydrogen peroxide $\left(\mathrm{H}_{2} \mathrm{O}_{2}\right)$, DMSO, L-sulforaphane (SF, \#S6317), 3-(4,5dimethylthiazol-2-yl)-2,5-diphenyltetrazolium bromide (MTT, \#M5655), propidium iodide (PI, \#81845) and the PI3K inhibitor LY294002 (\#440204) were purchased from Sigma (St Louis, MO, USA). Penicillin, streptomycin and 4',6-diamidino-2-phenylindole (DAPI, \#62247) were purchased from Thermo Fisher (Waltham, MA, USA), while Hoechst 33,342 (\#H3570), DCFH-DA (2'-7'dichlorofluorescin diacetate, \#D399) and lipofectamine 2000 transfection reagent (\#13778030) were also bought from Thermo Fisher but at a different site (Hanover Park, IL, USA). MNG (\#QP-1913) was purchased from Quality Phytochemicals LLC (East Brunswick, NJ, USA).

\subsection{Cell Culture}

Cells were cultured according to manufacturers' instructions. The ARE Reporter-HepG2 cell line contains a firefly luciferase gene under the control of ARE stably integrated into HepG2 cells. This cell line is validated for the response to the stimulation of tert-butylhydroquinone (TBHQ) and SF, and is used to monitor Nrf2 antioxidant response pathway activity and screen for activators or inhibitors of the Nrf2 antioxidant response pathway. Nrf2-AREHepG2 cells were cultured at $37^{\circ} \mathrm{C}$ in a humidified incubator with $5 \% \mathrm{CO}_{2}$, in EMEM with nonessential amino acids and supplemented with $10 \%$ FBS, penicillin and streptomycin. Cells were selected with the aminoglycoside antibiotic, G418 $(500 \mu \mathrm{g} / \mathrm{mL})$ and split every 4 to 5 days. EA.hy 926 cells were cultured in DMEM supplemented with $10 \%$ heat-inactivated FBS, penicillin $(100 \mathrm{U} / \mathrm{mL})$, and streptomycin $(100 \mathrm{U} / \mathrm{mL})$ at $37^{\circ} \mathrm{C}$ in a humidified atmosphere containing $95 \%$ air and $5 \% \mathrm{CO}_{2}$. All cells were from $<10$ passages.

\subsection{Luciferase Reporter Gene Assay}

The Nrf2-ARE-HepG2 stable cell line was seeded into 96-well plates at $4 \times 10^{4}$ per well in a final volume of $100 \mu \mathrm{L}$ MEM. Medium was replaced with fresh MEM after seeding for $24 \mathrm{~h}$ and the cells were treated with or without MNG $(5-80 \mu \mathrm{M})$. Plates were incubated 
for $24 \mathrm{~h}$, then $100 \mu \mathrm{L}$ ONE-Step Luciferase reagent (BPS Bioscience) was added to each well and the assay was performed according to manufacturer's instructions. Luminescence was detected using a luminometer (LUMIstar Galaxy BMG, Offenburg, Germany) and data are expressed as relative luminescence units (RLU) emitted from total assays. SF (5 $\mu \mathrm{M})$ was used as a positive control [13].

\subsection{Cell Viability Assay}

An MTT assay was performed to estimate cell viability. EA.hy926 cells $\left(1 \times 10^{4}\right.$ per well) were seeded in 96-well plates, cultured at $37^{\circ} \mathrm{C}$ in a $5 \% \mathrm{CO}_{2}$ incubator for $24 \mathrm{~h}$, and then incubated with or without MNG $(5-80 \mu \mathrm{M})$ for $24 \mathrm{~h}$. For induction of oxidative stress, cells were exposed to $\mathrm{H}_{2} \mathrm{O}_{2}$ at $0,100,250,400,550,700$ and $850 \mu \mathrm{M}$ for $6 \mathrm{~h}$. Compared with cell viability in the control group, $\mathrm{H}_{2} \mathrm{O}_{2}$ at $550 \mu \mathrm{M}$ caused about $50 \%$ decrease in cell viability. Thus, $\mathrm{H}_{2} \mathrm{O}_{2}$ at the concentration of $550 \mu \mathrm{M}$ was chosen for the follow-up experiments. To test cytoprotective effect of MNG, EA.hy926 cells were first treated with indicated concentration of MNG, then incubated with $\mathrm{H}_{2} \mathrm{O}_{2}(550 \mu \mathrm{M})$ for $6 \mathrm{~h}$. $20 \mu \mathrm{L}$ of MTT $(5 \mathrm{mg} / \mathrm{mL})$ in PBS was added to each well, and cells were further incubated at $37^{\circ} \mathrm{C}$ for $4 \mathrm{~h}$. The culture medium was carefully removed, and $200 \mu \mathrm{L}$ of DMSO was added per well to dissolve the formed precipitate. Plates were shaken for $10 \mathrm{~s}$, and absorbance was measured at the wavelength of $570 \mathrm{~nm}$ on a microplate reader (BIO-TEK instruments, Inc., Winooski, VT, USA) [39,40].

\subsection{Hoechst 33342/PI Fluorescent Staining}

EA.hy926 cells were plated at $1.5 \times 10^{4}$ cells/well in 96-well microplates (Greiner Bio-One, Frickenhausen, Germany) and incubated for $24 \mathrm{~h}$, and then the culture medium was removed. Compounds were prepared at various concentrations in 1\% FBS with phenol red-free DMEM and incubated for $24 \mathrm{~h}$. A sample of $550 \mu \mathrm{M} \mathrm{H}_{2} \mathrm{O}_{2}$ diluted in $1 \%$ FBS with phenol red-free DMEM was treated for $6 \mathrm{~h}$ for induction of oxidative stress. Cytotoxicity was measured by using Hoechst 33,342 and PI co-staining. Cells were stained with $2 \mu \mathrm{g} / \mathrm{mL}$ Hoechst 33,342 (excitation/emission of $350 \mathrm{~nm} / 461 \mathrm{~nm}$ ) for $30 \mathrm{~min}$ and $2 \mu \mathrm{g} / \mathrm{mL}$ PI (excitation/emission of 535/617 $\mathrm{nm}$ ) for $15 \mathrm{~min}$ in the dark. PI stains nuclei of dead cells, whereas Hoechst33342 stains nuclei of all cells. The fluorescent images were acquired by using an Operetta high-content imaging system (Perkin Elmer, Waltham, MA, USA) $[30,41]$.

\subsection{ROS Detection}

To monitor the intracellular accumulation of ROS, the fluorescence-generating probe DCFH-DA was used. Briefly, EA.hy926 cells seeded in 96-well plates at the density of $1.5 \times 10^{4}$ per well were cultured overnight. The cells were pretreated with various concentrations of MNG for $24 \mathrm{~h}$ followed by exposure to $550 \mu \mathrm{M} \mathrm{H}_{2} \mathrm{O}_{2}$ for $6 \mathrm{~h}$. After washing with PBS twice, cells were incubated with a serum-free medium containing $10 \mu \mathrm{M}$ DCFH-DA at $37^{\circ} \mathrm{C}$ for $30 \mathrm{~min}$, and then washed with PBS twice to remove extracellular DCFH-DA. Intracellular ROS were measured immediately using a microplate reader (BIO-TEK instruments, Inc., Winooski, VT, USA). Fluorescence staining was visualized on an Operetta high-content imaging system (PerkinElmer, Waltham, MA, USA) [30].

\subsection{Isolation of Nuclear and Cytoplasmic Extract}

The cells $\left(1 \times 10^{6}\right.$ cells per well in $60 \mathrm{~mm}$ dishes $)$ were treated with MNG at various concentrations $(0,5,10,20,40$ and $80 \mu \mathrm{M})$ and SF $(5,10$ and $20 \mu \mathrm{M})$ for $24 \mathrm{~h}$. The nuclear extraction was prepared using an NE-PER Nuclear and Cytoplasmic Extraction Reagent kit according to the manufacturer's instruction. The resulting supernatant, constituting the cytoplasmic and nuclear extract, was used for the subsequent experiments. The protein concentrations were determined by BCA protein assay (bicinchoninic acid protein assay). 


\subsection{Western Blot Analysis}

Total protein was extracted from the cells and prepared with RIPA buffer. Nuclear or cytoplasmic proteins were isolated as described above. Protein samples were boiled for 5 min at $95^{\circ} \mathrm{C}$. The protein concentrations were quantified by the BCA protein assay. In brief, samples with the same amount of proteins were separated on $10 \%$ polyacrylamide gel. The proteins were then electrophoretically transferred at $15 \mathrm{~V}$ at RT onto a NC membrane. The blotted membranes were blocked in 5\% nonfat dry milk in TBST for $1 \mathrm{~h}$ and then incubated overnight at $4{ }^{\circ} \mathrm{C}$ with the indicated primary antibodies. After three washes with TBST, the membranes were then incubated with corresponding secondary antibodies for $1 \mathrm{~h}$ and bands were visualized and analyzed by the LI-COR odyssey image system (Lincoln, NV, USA). Each Western blot analysis was performed in triplicate [42].

\subsection{Real-Time PCR Analysis}

Total RNA was extracted from the treated cells $\left(1 \times 10^{6}\right.$ cells per well in $60 \mathrm{~mm}$ dishes) by using the TRIzol reagent and RNeasy Mini Kit. cDNA was prepared with iScript cDNA synthesis kit. Multi-gene transcriptional profiling with quantitative RT-PCR was performed with iTag universal SYBR green supermix and Bio-Rad CFX96 real-time system. All reactions were performed in triplicate. The relative expression of target genes was normalized to the expression of housekeeping gene GAPDH, calculated by the $2^{-\Delta \Delta C T}$ method and given as ratio compared with control. Quantitative real-time PCR was performed using the following primers: Nrf2, F: 5'-GAGACAGGTGAATTTCTCCCAAT-3', R: 5'-TTTGGGAATGTGGGCAAC-3'; HO-1, F: 5'-GCTGAGTTCATGAGGAACTTTCAG-3' ${ }^{\prime}$ R: 5'-TGGTACAGGGAGGCCATCAC-3'; NQO1, F: 5' -ATGTATGACAAAGGACCCTTCC-3', R: 5'-TCCCTTGCAGAGAGTACATGG-3'; GAPDH, F: 5'-GAGCCAAAAGGGTCATCATC$3^{\prime}$, R: 5'-TAACAGTTGGTGGTGCAGG-3' [41,43].

\subsection{Immunofluorescence Analysis}

EA.hy926 cells were seeded at $1 \times 10^{4}$ cells/well in 96-well microplates overnight and then treated with various concentrations of MNG or SF. After $24 \mathrm{~h}$, the cells were fixed with $4 \%$ paraformaldehyde for $30 \mathrm{~min}$ followed by $0.3 \%$ Triton to punch at RT for $30 \mathrm{~min}$. After washing 3 times with PBS buffer and blocking with 5\% BSA for $1 \mathrm{~h}$, the cells were incubated with a primary antibody of anti-Nrf2 (1:500) overnight at $4{ }^{\circ} \mathrm{C}$ followed by incubation of an Alexa Fluor 488-conjugated goat anti-rabbit monoclonal fluorescent secondary antibody (1:1000) for $1 \mathrm{~h}$ at RT. After washing three times with PBS, the cells were stained with DAPI for $15 \mathrm{~min}$. The plate was scanned by the Operetta high-content imaging system (PerkinElmer), and the Harmony software (version 4.1) was used to calculate the percentage of nuclear translocation [44].

\subsection{RNA Interference of $N r f 2$}

Transient transfection of siRNA was performed with the lipofectamine 2000 transfection reagent according to the manufacturer's instructions. In brief, the cells were seeded in a 6-well culture plate $\left(3 \times 10^{5}\right.$ cells per well) to reach $60 \%$ confluency and transfected with negative control (NC) siRNA or Nrf2 siRNA. The transfected cells were prepared and the expressions of Nrf2 and target genes were analyzed [45].

\subsection{Statistical Analysis}

Unless otherwise mentioned, all data exhibited in the study were expressed as mean \pm SEM from at least 3 independent experiments, each in triplicate for individual treatment or dosage. Statistical differences between two groups (usually the control and an experimental group) were evaluated by $t$-test. One-way ANOVA was used to evaluate the differences between multiple groups, and $p<0.05$ was considered as statistical significance. 
Supplementary Materials: The following are available, Figure S1: MS spectrum of MNG, Figure S2: ${ }^{1} \mathrm{H}$ NMR spectrum (400 MHz) of MNG in DMSO- $d_{6}$, Figure S3: Cytotoxicity of MNG (left) and SF against EA.hy926 cells.

Author Contributions: Conceptualization, Y.L. and S.C.; methodology, X.W., Y.C. and S.C.; software, X.W.; validation, X.W., J.X., Y.Y., Y.L. and S.C.; formal analysis, X.W. and S.C.; investigation, X.W. and Y.C.; resources, J.X. and Y.Y.; data curation, X.W. and J.X.; writing-original draft preparation, X.W.; writing-review and editing, X.W. and S.C.; visualization, X.W., J.X., Y.Y., Y.L. and S.C.; supervision, S.C.; project administration, J.X. and S.C.; funding acquisition, Y.L. and S.C. All authors have read and agreed to the published version of the manuscript.

Funding: This research was funded by Jing Brand Research Institute, Jing Brand Co., Ltd. (Daye, China) for financial support (20190128).

Institutional Review Board Statement: Not applicable.

Informed Consent Statement: Not applicable.

Data Availability Statement: Data sharing not available.

Acknowledgments: We thank Ingo Ko'omoa-Lange for his advice and help in using the Operetta high content image.

Conflicts of Interest: The authors declare no conflict of interest.

Sample Availability: Samples generated from Jing Liqueur but not the pure compounds are available from the authors.

\begin{abstract}
Abbreviations and Nomenclature
Antioxidant response element (ARE); bicinchoninic acid assay (BCA assay); $4^{\prime}, 6$-diamidino2-phenylindole (DAPI); 2'-7'-Dichlorofluorescin diacetate (DCFH-DA); Dulbecco's modified eagle medium (DMEM); dimethyl sulfoxide (DMSO); 1,1-Diphenyl-2-picrylhydrazyl (DPPH); Eagle's minimum essential medium (EMEM); EA.hy926: a type of human umbilical vein endothelial cell line; fetal bovine serum (FBS); glutamate-cysteine ligase (GCL); Heme oxygenase 1 (HO-1), human umbilical vein endothelial cells (HUVEC); Kelch ECH associating protein 1 (Keap1); musculoaponeurotic fibrosarcoma (Maf); methylnissolin-3-O- $\beta$-D-glucopyranoside (MNG); 3-(4,5-dimethylthiazol-2-yl)-2,5-diphenyltetrazolium bromide (MTT); negative control (NC) membrane; NAD(P)H:quinone oxidoreductase 1 (NQO1); nuclear factor erythroid 2related factor 2 (Nrf2); PCl12: a cell line derived from a pheochromocytoma of the rat adrenal medulla; propidium iodide (PI); phosphoinositide 3-kinase (PI3K); radioimmunoprecipitation assay buffer (RIPA buffer); relative luminescence units (RLU); reactive oxygen species (ROS); small interference RNAs (siRNA); L-sulforaphane (SF); tert-butylhydroquinone (TBHQ); trisbuffered saline containing $0.1 \%$ tween-20 (TBST); thioredoxin 1 (Trx1); thioredoxin reductase 1 (TrxR1).
\end{abstract}

\title{
References
}

1. Li, R.; Jia, Z.; Trush, M.A. Defining ROS in Biology and Medicine. React. Oxyg. Species 2016, 1, 9-21.

2. Zhai, K.-F.; Duan, H.; Chen, Y.; Khan, G.J.; Cao, W.-G.; Gao, G.-Z.; Shan, L.-L.; Wei, Z.-J. Apoptosis effects of imperatorin on synoviocytes in rheumatoid arthritis through mitochondrial/caspase-mediated pathways. Food Funct. 2018, 9, 2070-2079. [CrossRef] [PubMed]

3. Tu, W.; Wang, H.; Li, S.; Liu, Q.; Sha, H. The Anti-Inflammatory and Anti-Oxidant Mechanisms of the Keap1/Nrf2/ARE Signaling Pathway in Chronic Diseases. Aging Dis. 2019, 10, 637-651. [CrossRef]

4. Zhai, K.-F.; Duan, H.; Khan, G.J.; Xu, H.; Han, F.-K.; Cao, W.-G.; Gao, G.-Z.; Shan, L.-L.; Wei, Z.-J. Salicin from Alangium chinense Ameliorates Rheumatoid Arthritis by Modulating the Nrf2-HO-1-ROS Pathways. J. Agric. Food Chem. 2018, 66, 6073-6082. [CrossRef] [PubMed]

5. Motohashi, H.; Yamamoto, M. Nrf2-Keap1 defines a physiologically important stress response mechanism. Trends Mol. Med. 2004, 10, 549-557. [CrossRef]

6. Kensler, T.W.; Wakabayashi, N.; Biswal, S. Cell survival responses to environmental stresses via the Keap1-Nrf2-ARE pathway. Annu. Rev. Pharmacol. Toxicol. 2007, 47, 89-116. [CrossRef]

7. Suzuki, T.; Motohashi, H.; Yamamoto, M. Toward clinical application of the Keap1-Nrf2 pathway. Trends Pharmacol. Sci. 2013, 34, 340-346. [CrossRef] 
8. Itoh, K.; Mimura, J.; Yamamoto, M. Discovery of the negative regulator of Nrf2, Keap1: A historical overview. Antioxid. Redox Signal. 2010, 13, 1665-1678. [CrossRef]

9. McMahon, M.; Itoh, K.; Yamamoto, M.; Hayes, J.D. Keap1-dependent proteasomal degradation of transcription factor Nrf2 contributes to the negative regulation of antioxidant response element-driven gene expression. J. Biol. Chem. 2003, 278, 2159221600. [CrossRef]

10. Li, W.; Yu, S.; Liu, T.; Kim, J.-H.; Blank, V.; Li, H.; Kong, A.-N.T. Heterodimerization with Small Maf Proteins Enhances Nuclear Retention of Nrf2 via Masking the NESzip Motif. Biochim. Biophys. Acta. 2008, 1783, 1847-1856. [CrossRef]

11. Burgering, B.M.T.; Kops, G.J.P.L. Cell Cycle and Death Control: Long Live Forkheads. Trends Biochem. Sci. 2002, 27, 352-360. [CrossRef]

12. Li, H.; Tang, Z.; Chu, P.; Song, Y.; Yang, Y.; Sun, B.; Niu, M.; Qaed, E.; Shopit, A.; Han, G.; et al. Neuroprotective Effect of Phosphocreatine on Oxidative Stress and Mitochondrial Dysfunction Induced Apoptosis in Vitro and in Vivo: Involvement of Dual PI3K/Akt and Nrf2/HO-1 Pathways. Free Radical Biol. Med. 2018, 120, 228-238. [CrossRef] [PubMed]

13. Cai, Y.; Xu, J.; Chen, M.; Wang, D.; Yang, Y.; Manavalan, A.; Wu, X.; Liu, Y.; Cao, S. Compound Analysis of Jing Liqueur and Nrf2 Activation by Jing Liqueur-One of the Most Popular Beverages in China. Beverages 2020, 6, 1. [CrossRef]

14. Guo, S.-B.; Du, X.-M.; Jian, L.-Y. Studies on purification process of total saponins in Radix Astragali with resin and structural identification of compounds. Asian J. Chem. 2014, 26, 4610-4614. [CrossRef]

15. Auyeung, K.K.; Han, Q.-B.; Ko, J.K. Astragalus membranaceus: A Review of its Protection Against Inflammation and Gastrointestinal Cancers. Am. J. Chin. Med. 2016, 44, 1-22. [CrossRef]

16. Yu, D.; Duan, Y.; Bao, Y.; Wei, C.; An, L. Isoflavonoids from Astragalus mongholicus protect PC12 cells from toxicity induced by L-glutamate. J. Ethnopharmacol. 2005, 98, 89-94. [CrossRef] [PubMed]

17. Xu, X.; Li, F.; Zhang, X.; Li, P.; Zhang, X.; Wu, Z.; Li, D. In vitro synergistic antioxidant activity and identification of antioxidant components from Astragalus membranaceus and Paeonia lactiflora. PLoS ONE 2014, 9, e96780. [CrossRef]

18. Nguyen, T.; Nioi, P.; Pickett, C.B. The Nrf2-antioxidant response element signaling pathway and its activation by oxidative stress. J. Biol. Chem. 2009, 284, 13291-13295. [CrossRef]

19. Yamamoto, M.; Kensler, T.W.; Motohashi, H. The KEAP1- NRF2 system: A thiol-based sensor-effector apparatus for maintaining redox homeostasis. Physiol. Rev. 2018, 98, 1169-1203. [CrossRef] [PubMed]

20. Di Marzo, N.; Chisci, E.; Giovannoni, R. The Role of Hydrogen Peroxide in Redox-Dependent Signaling: Homeostatic and Pathological Responses in Mammalian Cells. Cells 2018, 7, 156. [CrossRef]

21. Wang, Y.; Wu, Y.; Wang, Y.; Fu, A.; Gong, L.; Li, W.; Li, Y. Bacillus amyloliquefaciens SC06 Alleviates the Oxidative Stress of IPEC-1 via Modulating Nrf2/Keap1 Signaling Pathway and Decreasing ROS Production. Appl. Microbiol. Biotechnol. 2017, 101, 3015-3026. [CrossRef] [PubMed]

22. Zhai, K.-F.; Duan, H.; Cui, C.-Y.; Cao, Y.-Y.; Si, J.-L.; Yang, H.-J.; Wang, Y.-C.; Cao, W.-G.; Gao, G.-Z.; Wei, Z.-J. Liquiritin from Glycyrrhiza uralensis Attenuating Rheumatoid Arthritis via Reducing Inflammation, Suppressing Angiogenesis, and Inhibiting MAPK Signaling Pathway. J. Agric. Food Chem. 2019, 67, 2856-2864. [CrossRef] [PubMed]

23. Tabei, Y.; Murotomi, K.; Umeno, A.; Horie, M.; Tsujino, Y.; Masutani, B.; Yoshida, Y.; Nakajima, Y. Antioxidant Properties of 5Hydroxy-4-Phenyl-Butenolide via Activation of Nrf2/ARE Signaling Pathway. Food Chem. Toxicol. 2017, 107, 129-137. [CrossRef]

24. Hou, D.-X.; Korenori, Y.; Tanigawa, S.; Yamada-Kato, T.; Nagai, M.; He, X.; He, J. Dynamics of Nrf2 and Keap1 in AREMediated NQO1 Expression by Wasabi 6-(Methylsulfinyl)hexyl Isothiocyanate. J. Agric. Food Chem. 2011, 59, 11975-11982. [CrossRef] [PubMed]

25. Wang, L.; Chen, Y.; Sternberg, P.; Cai, J. Essential Roles of the PI3 Kinase/Akt Pathway in Regulating Nrf2-Dependent Antioxidant Functions in the RPE. Invest. Ophthalmol. Vis. Sci. 2008, 49, 1671-1678. [CrossRef]

26. Zou, W.; Chen, C.; Zhong, Y.; An, J.; Zhang, X.; Yu, Y.; Yu, Z.; Fu, J. PI3K/Akt Pathway Mediates Nrf2/ARE Activation in Human L02 Hepatocytes Exposed to Low-Concentration HBCDs. Environ. Sci. Technol. 2013, 47, 12434-12440. [CrossRef]

27. Han, D.; Chen, W.; Gu, X.; Shan, R.; Zou, J.; Liu, G.; Shahid, M.; Gao, J.; Han, B. Cytoprotective Effect of Chlorogenic Acid against Hydrogen Peroxide-Induced Oxidative Stress in MC3T3-E1 Cells through PI3K/Akt-Mediated Nrf2/HO-1 Signaling Pathway. Oncotarget 2017, 8, 14680-14692. [CrossRef]

28. Li, W.; Sun, Y.N.; Yan, X.T.; Yang, S.Y.; Kim, S.; Lee, Y.M.; Koh, Y.-S.; Kim, Y.H. Flavonoids from Astragalus membranaceus and their inhibitory effects on LPS-stimulated pro-inflammatory cytokine production in bone marrow-derived dendritic cells. Arch. Pharm. Res. 2014, 37, 186-192. [CrossRef]

29. Wang, H.; Chen, W. Anti-Aging Pharmaceutical a Composition. CN Patent 104,523,733, 22 April 2015.

30. Zhu, M.; Li, J.; Wang, K.; Hao, X.; Ge, R.; Li, Q. Isoquercitrin Inhibits Hydrogen Peroxide-Induced Apoptosis of EA.hy926 Cells via the PI3K/Akt/GSK3 $\beta$ Signaling Pathway. Molecules 2016, 21, 356. [CrossRef]

31. Bischoff, L.J.M.; Kuijper, I.A.; Schimming, J.P.; Wolters, L.; Ter Braak, B.; Langenberg, J.P.; Noort, D.; Beltman, J.B.; van de Water, B. A systematic analysis of Nrf2 pathway activation dynamics during repeated xenobiotic exposure. Arch. Toxicol. 2019, 93, 435-451. [CrossRef]

32. Hsieh, T.C.; Lu, X.; Wang, Z.; Wu, J.M. Induction of quinone reductase NQO1 by resveratrol in human K562 cells involves the antioxidant response element ARE and is accompanied by nuclear translocation of transcription factor Nrf2. Med. Chem. 2006, 2, 275-285. [CrossRef]

33. Li, B.; Tian, S.; Liu, X.; He, C.; Ding, Z.; Shan, Y. Sulforaphane protected the injury of human vascular endothelial cell induced by LPC through up-regulating endogenous antioxidants and phase II enzymes. Food Funct. 2015, 6, 1984-1991. [CrossRef] 
34. Yang, G.; Chang, C.C.; Yang, Y.; Yuan, L.; Xu, L.; Ho, C.T.; Li, S. Resveratrol Alleviates Rheumatoid Arthritis via Reducing ROS and Inflammation, Inhibiting MAPK Signaling Pathways, and Suppressing Angiogenesis. J. Agric. Food Chem. 2018, 66, 12953-12960. [CrossRef] [PubMed]

35. Wang, W.; Wang, Y.-R.; Chen, J.; Chen, Y.-J.; Wang, Z.-X.; Geng, M.; Xu, D.-C.; Wang, Z.-Y.; Li, J.-H.; Xu, Z.-D.; et al. Pterostilbene Attenuates Experimental Atherosclerosis through Restoring Catalase-Mediated Redox Balance in Vascular Smooth Muscle Cells. J. Agric. Food Chem. 2019, 67, 12752-12760. [CrossRef] [PubMed]

36. Luo, X.; Zhang, H.; Duan, Y.; Chen, G. Protective Effects of Radish (Raphanus sativus L.) Leaves Extract against Hydrogen PeroxideInduced Oxidative Damage in Human Fetal Lung Fibroblast (MRC-5). Cells. Biomed. Pharmacother. 2018, 103, 406-414. [CrossRef]

37. Mateés, J.M. Effects of Antioxidant Enzymes in the Molecular Control of Reactive Oxygen Species Toxicology. Toxicology 2000, 153, 83-104. [CrossRef]

38. Kenessey, A.; Kaie Ojamaa, K. Thyroid hormone stimulates protein synthesis in the cardiomyocyte by activating the Akt-mTOR and p70S6K pathways. J. Biol. Chem. 2006, 281, 20666-20672. [CrossRef]

39. Gu, L.; Ye, P.; Li, H.; Wang, Y.; Xu, Y.; Tian, Q.; Lei, G.; Zhao, C.; Gao, Z.; Zhao, W.; et al. Lunasin attenuates oxidant-induced endothelial injury and inhibits atherosclerotic plaque progression in ApoE - / - mice by up-regulating heme oxygenase-1 via PI3K/Akt/Nrf2/ARE pathway. FASEB J. 2019, 33, 4836-4850. [CrossRef] [PubMed]

40. Fang, C.; Zhang, B.B.; Han, L.; Gao, C.F.; Wang, M. D-Fagomine attenuates high glucose-induced endothelial cell oxidative damage by upregulating the expression of PGC-1 $\alpha$. J. Agric. Food Chem. 2018, 66, 2758-2764. [CrossRef]

41. Hou, Y.; Li, X.; Peng, S.; Yao, J.; Bai, F.; Fang, J. Lipoamide Ameliorates Oxidative Stress via Induction of Nrf2/ARE Signaling Pathway in PC12 Cells. J. Agric. Food Chem. 2019, 67, 8227-8234. [CrossRef] [PubMed]

42. Senger, D.R.; Li, D.; Jaminet, S.C.; Cao, S. Activation of the Nrf2 Cell Defense Pathway by Ancient Foods: Disease Prevention by Important Molecules and Microbes Lost from the Modern Western Diet. PLoS ONE 2016, 11, e0148042. [CrossRef]

43. Yan, C.; Zhang, X.; Miao, J.; Yuan, H.; Liu, E.; Liang, T.; Li, Q. Farrerol Directly Targets GSK-3 $\beta$ to Activate Nrf2-ARE Pathway and Protect EA.hy926 Cells against Oxidative Stress-Induced Injuries. Oxid. Med. Cell. Longev. 2020, 2020, 5967434. [CrossRef] [PubMed]

44. Luo, J.F.; Shen, X.Y.; Lio, C.K.; Dai, Y.; Cheng, C.S.; Liu, J.X.; Yao, Y.D.; Yu, Y.; Xie, Y.; Luo, P.; et al. Activation of Nrf2/HO-1 Pathway by Nardochinoid C Inhibits Inflammation and Oxidative Stress in Lipopolysaccharide-Stimulated Macrophages. Front. Pharmacol. 2018, 9, 911. [CrossRef] [PubMed]

45. Zhang, L.; Zhang, H.; Li, X.; Jia, B.; Yang, Y.; Zhou, P.; Li, P.; Chen, J. Miltirone protects human EA.hy926 endothelial cells from oxidized low-density lipoprotein-derived oxidative stress via a heme oxygenase-1 and MAPK/Nrf2 dependent pathway. Phytomedicine 2016, 23, 1806-1813. [CrossRef] 